\title{
Rehabilitation effects in patients with total hip replacement: a systematic review and meta-analysis
}

\author{
Carlo TUGNI ${ }^{1}$, Julita SANSONI ${ }^{2}$, Nicola VANACORE ${ }^{3}$, \\ Donatella VALENTE ${ }^{4}$, Giovanni GALEOTO 1 *
}

${ }^{1}$ Sapienza University, Rome, Italy; ${ }^{2}$ Department of Public Health and Infection Disease, Sapienza University, Rome, Italy; ${ }^{3}$ National Institute of Health, Rome, Italy; ${ }^{4}$ Department of Human Neurosciences, Sapienza University, Rome, Italy

*Corresponding author: Giovanni Galeoto, piazzale Aldo Moro 5, Rome, Italy. E-mail: giovanni.galeoto@uniroma1.it

\section{A B S T R A C T}

INTRODUCTION: Assess effectiveness and times of total hip replacement rehabilitation treatment through a systematic review with meta-analysis

EVIDENCE ACQUISITION: Bibliographical research has been made with the following search engines: PubMed, Pedro and Cinalh. For pool analysis evaluation, it has been used the standardized mean difference (SMD). Heterogeneity between studies had been controlled through the $\mathrm{I}^{2}$ test.

EVIDENCE SYNTHESIS: Fourteen of those studies have met the inclusion criteria. These have been divided into three different groups to assess different aspects of THR patient rehabilitation program: a rehabilitation path — entirely made and supervised by a physiotherapist - has been compared with an unsupervised one; an intensive rehabilitation path has been compared with a standard one and the early beginning of the treatment has been compared with a standard one. CONCLUSIONS: considering the great rise of THR surgeries, is important to minimize costs and logistic efforts for the postoperative rehabilitation program ensuring identical or better outcomes.

Thinking of that and of RCTs data it seems evident that, while recognizing physiotherapist as a key element of the rehabilitation program, postoperative treatment should focus on an unsupervised rehabilitation program after a first period of a supervised intensive rehabilitation program.

(Cite this article as: Tugni C, Sansoni J, Vanacore N, Valente D, Galeoto G. Rehabilitation effects in patients with total hip replacement: a systematic review and meta-analysis. Minerva Ortop Traumatol 2019;70:000-000. DOI: 10.23736/S03943410.19.03929-8)

KEY WORDS: Rehabilitation; Arthroplasty, replacement, hip; Systematic reviews as topic.

\section{Introduction}

$\mathrm{I}_{\mathrm{n}}^{\mathrm{n}}$ n Italy, as well as in the US and in most of the Western countries, ${ }^{1,2}$ osteoarthritis (OA) is the most common articular disease. ${ }^{3} \mathrm{OA}$ affects hips less frequently compared to knees and hands, but when hips are involved, they strongly influence quality of life. ${ }^{4}$

Most common OA symptoms are pain, ${ }^{5-7}$ restrictions on physical functions, ${ }^{8-10}$ difficulties in activities of daily life 6,9 and weakening of the peri-articular musculature. ${ }^{11}$ The American Col- lege of Rheumatology warns to treat these symptoms conservatively (drugs and physiotherapy); just when this approach fails, it will be suggested a THR surgery. ${ }^{12}$

After THR, patients' expect a significant reduction of pain and the ability to undertake normal tasks involved in daily living. ${ }^{13}, 14 \mathrm{~A}$ variety of studies show the THR positive effects: in fact the majority of patients undergoing THR experience a relevant pain relief ${ }^{15-17}$ and a better gait after three months from the surgery. ${ }^{18-20}$

During the last fifteen years in many European 
countries, it has been noticed a steady increase in THR application, either because of an increase in life expectancy or because of THR, when clinically indicated, is able to improve quality of life. ${ }^{13,14}$ Despite that, long term outcomes show muscular weakness and physical functions deficit $^{21-24}$ very often, years after THR surgery, gait analysis is still not comparable to that of healthy same age peers. ${ }^{24-26}$

The rehabilitation program is usually adapted according to patient needs, empirical based practice and best EBMs. Despite lots of THR rehabilitation studies regarding outcomes- related to different quality and/or quantity of treatmentEBMs does not configure a gold standard for muscle strength, physical functions, quality of life's recovery. This fact implies that rehabilitation strategies and choices are sometimes based just on empirical based practice. ${ }^{27}$ The so called "standard" postsurgery rehabilitation treatment is based on isometric exercises of hip abductors and quadriceps muscles, articular ROM exercises, muscle stretching exercises, postural movements, gait training and general suggestions for daily life activities. ${ }^{28,}{ }^{29}$ In Italy, as well in lots of Western countries, after hospital resignation it is possible to keep following the rehabilitation program either in an outpatient or in a home-based regime, with or without any physiotherapist supervision.

The aim of this study was to evaluate, whether there are evidences to identify the best post-THR rehabilitation program, through a systematic review of RCTs, and metanalysis, taking into consideration the quantitative, qualitative and intensity treatment aspects. This rehabilitation program can be created according to the daily activities, quality of life and length of stay (LOS), outcomes.

\section{Evidence acquisition}

\section{Search strategy for identification of studies}

Led by the PRISMA checklist ${ }^{30}$ on the $31^{\text {st }}$ of January 2016 we made a simultaneous research on three different search engines: PubMed (since 1949), PEDro physiotherapy evidence database and CINAHL (since 1982) to select relevant RCTs (Table I).

\section{Eligibility criteria}

It has been selected: 1) randomized clinical trials that took into account physiotherapy treatments for THR patients who underwent surgery for OA; 2) studies where at least the $85 \%$ of the sample pa-

TABLE I.-Search strategy.

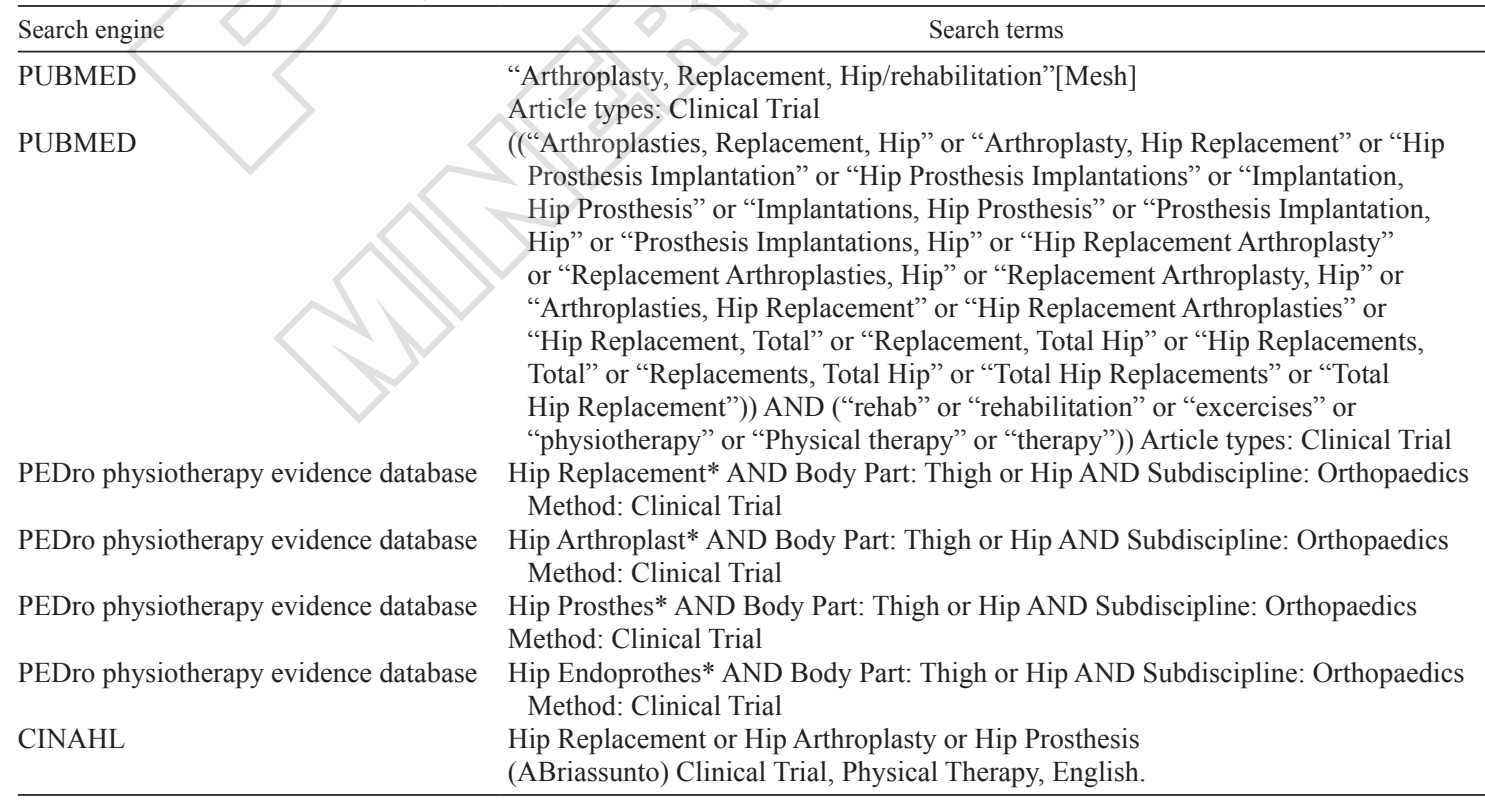


tients underwent surgery for OA; 3 ) articles either in English or Italian; 4) studies where the analyzed sample of patients were older than sixty years; 5) RTCTs that evaluate a "particular" rehabilitation program compared to a "standard" one, or compared two or more types or intensity of treatment; 6) articles in which treatments were well described, as good as to let them possible to be reproduced.

It has been excluded: 1) studies where the treatment was purely finalized to prevent deep vein thrombosis; 2) studies where one or more patients underwent a resurface or partial hip replacement; 3) studies where the rehabilitation program required any electromedical device (e.g. muscular electrostimulation, kinetec, ergometer...); 4) studies in which were included a preoperative treatment; 5) studies where were not assessed either the length of stay (LOS), or one or more quality life outcomes.

\section{Risk of bias assessment}

Methodical quality of the studies has been assessed through the Jadad Scale, with a score between 0 and 5. Two Authors have independently assessed bias risk of the included articles; every disagreement, whether present, was solved with the introduction of a third opinion.

\section{Statistical analysis}

To evaluate treatment effects, whether possible, has been used the SMD. All the results have been compared by applying the random effects model with a confidence interval at $95 \%$ (CI).

We planned to test heterogeneity between comparable evidences using a heterogeneity test $\left(\mathrm{I}^{2}\right)$ considered statistically significant with a $\mathrm{P}$ value $<0.05$.

It has been interpreted as follows: $0 \%$ to $40 \%$, low heterogeneity; $30 \%$ to $60 \%$, mid heterogeneity; $50 \%$ to $75 \%$, reasonable heterogeneity; $75 \%$ to $100 \%$, excellent heterogeneity. Whether $\mathrm{I}^{2}$ test was not significant $(\mathrm{P}>0.05)$, we would have conduct sensibility analysis to evaluate potential heterogeneity sources. All statistical analyses have been done with the RevMan 5.3 program.

\section{Data items of included studies}

For each included study we have analyzed the following items: sample size, average age of the participants, type of treatment, type and dose of treatment of all groups, follow-up, outcome and Jadad Score (Oxford Quality Scoring System).

\section{Evidence synthesis}

From the research made on the above mentioned three search engines we have obtained 1211 articles: 226 have been excluded as duplicates and 826 have been excluded as not inherent to this study. Out of the 158 promoted articles the full-text has been read, 144 of these have been excluded since did not match the inclusion criteria (Figure 1).

\section{Included articles description}

The fourteen articles included in this systematic review (Table I) are multilayered as follows: six articles compare a rehabilitation path entirely performed and supervised by a physiotherapist, with one just partially or non-supervised;31-36 five articles compare an intensive rehabilitation program with a "standard" one; $37-41$ three articles compare an early start of the rehabilitation program with a standard one. ${ }^{42-44}$

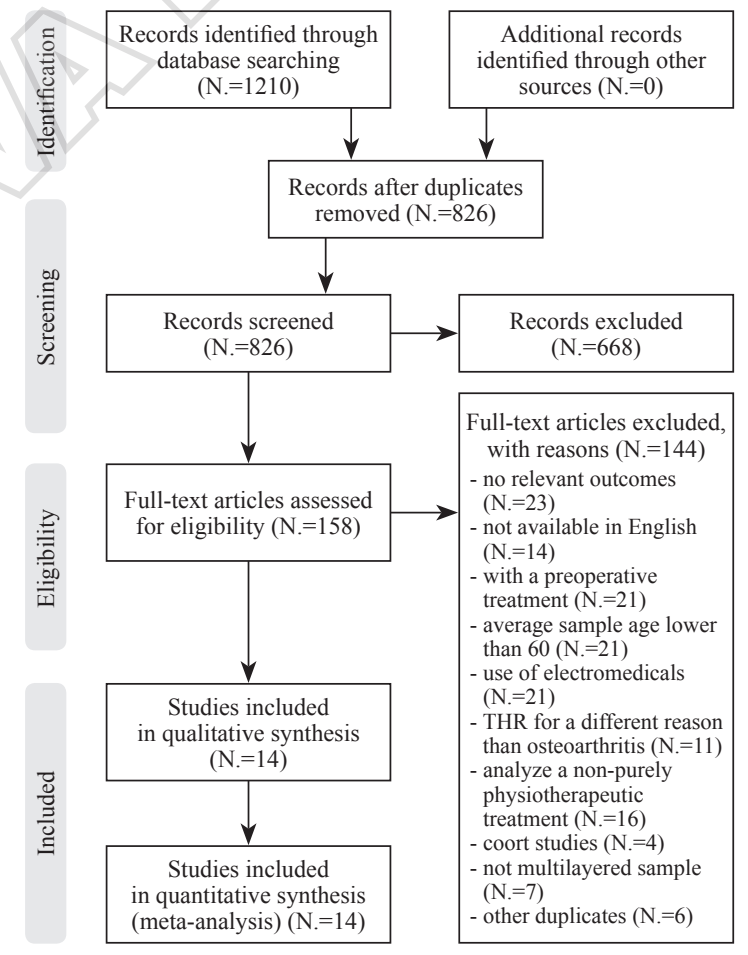

Figure 1.-Flow-chart of the study. 


\section{Bias risk}

To assess bias risk has been used the Jadad Scale. Among the six studies included in the first stratification, two of them have reported a score of 3, two have reported a score of two and other two a score of one. Related to the second stratification, two studies have reported a score of three, one has reported a score of two and other two a score of one. Among the third stratification studies, two have reported a score of three and one a score of one (Table II).

\section{Summary results}

\section{Outcomes evaluation}

SUPERVISED REHABILITATION PROGRAM VS. UNSUPERVISED ONE.

The analyzed studies compare a supervised rehabilitation program with one that - studies by Smith et al. 34,35 excluded - does not provide any physiotherapy supervision.

Galea et al. ${ }^{36}$ and Heiberg et al. ${ }^{33}$ studies analyze treatments provided respectively three and one month after surgery, while in the other studies treatments are provided in the right short term after hip replacement. In the study by Mikkelsen et al.,31 with the same quantity of exercises in both groups HOOS Scale at short, mid and long term, it does not show any statistically significant differences between groups; in the study by Umpierres et al.,32 with the same quantity of exercises in both groups, 20 days after surgery supervised treatment, it had better effects just about one of the 8 SF-36 sub-scales (Bodily pain), while mid- and long-terms outcomes are not recorded; Smith ${ }^{34,} 35$ underlines that adding unsupervised bed exercises made during the stay in hospital, do not influence any patient's outcome. Heiberg et al. ${ }^{33}$ said that gait training administered three months after the operatio - in comparison to a single phone recommendation - it leads to better outcomes only with regard to HHS short term follow-up, there are not differences between-group regarding HOOS and long-term HHS follow-up; finally the analysis by Galea et al. 36 analyzes a two months long supervised physio-therapeutic treatment compared to an unsupervised home-based exercise program, both of them initiated one month post-surgery. Therefore, the authors concluded that direct physiotherapy treatment does not provide any better effect with regard to WOMAC and AQoL at three months follow-up.

Concerning mid-term (2/6 and months) HOOS meta-analysis data we have had two studies for a total amount of 130 patients. Pool analysis average shows that supervised treatment has led to not statistically significant better outcomes (-1.91 points, CI -7.92-4.11; $\mathrm{P}=0.53$ ) (Figure 2). For long-term ( $>6$ months) HOOS meta-analysis

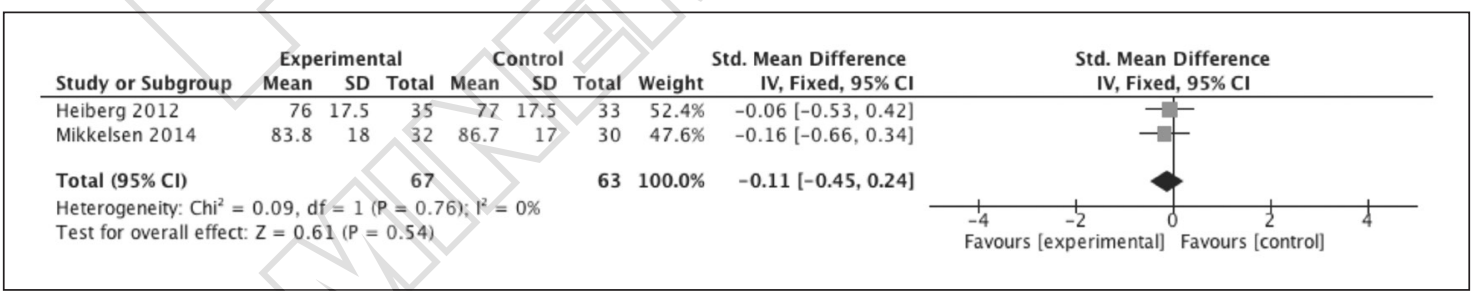

Figure 2.-HOOS analysis; 2-6 months follow-up.

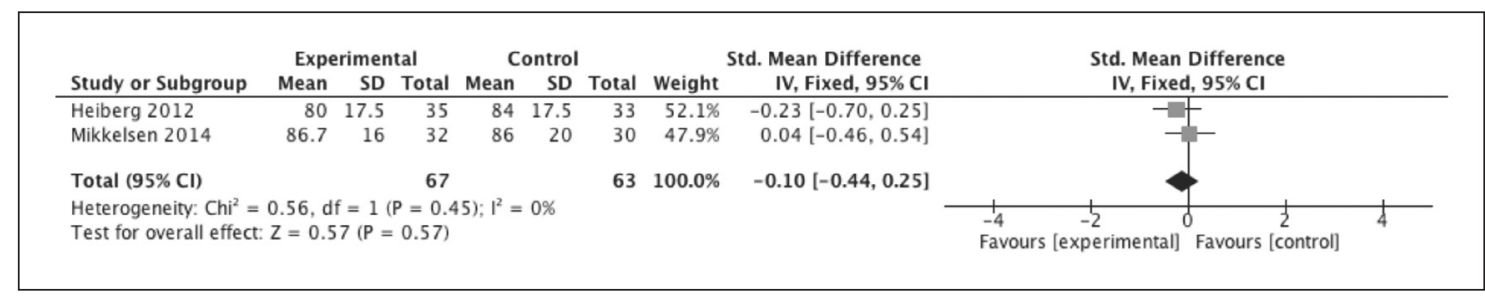

Figure 3.-HOOS analysis; $>6$ months follow-up. 
data we have had the same two studies. Pool analysis average shows that a supervised rehabilitation program has also led to a not statistically significant better outcomes (-1.85 points, CI -7.92-4.28; $\mathrm{P}=0.55$ ) (Figure 3 ).

INTENSIFIED REHABILITATION PROGRAM VS STANDARD ONE.

Five studies have been included in this stratification, four of them have used "standard" hospital rehabilitation as control treatment while the remaining one ${ }^{38}$ uses an unsupervised home-based program. Suetta ${ }^{37}$ added to study group rehabilitation program three unilateral quadriceps strengthening sessions per week. Larsen ${ }^{40,41}$ and Stockton ${ }^{39}$ included a redoubling amount of rehabilitation minutes.

Compared to control groups, results show a reduction in LOS of six days in the study by Suetta et al., 37 a reduction of 2.9 days in Larsen et al. ${ }^{41}$ and of 3.1 days in Larsen et al.;40 in the study by Stockton et al., ${ }^{39}$ no differences are notable. In ${ }^{40,41}$ EQ-5D Scale shows better QoL outcomes following an accelerated program. With regard to Mikkelsen et al. ${ }^{38}$ where study group follow a thera-band exercise program added to the standard home based one, EQ-5D and WOMAC data, one and three months after surgery, do not show any statistically significant difference compared to control group.

Three months EQ-5D follow-up data of three studies with a total of 198 patients have been meta-analyzed. Pool analysis average shows statistically significant better outcomes after an intensified rehabilitation program $(0.48$ points, $\mathrm{CI}$ -0.19-0.76; $\mathrm{P}=0.0009$ ) (Figure 4).

LOS data meta-analysis has been made on four studies (238 pt). Pool analysis average shows that an intensified rehabilitation program has led to statistically significant shorter LOS (-1.21 points, CI -1.49-0.92; $\mathrm{P}<0.00001$ ) (Figure 5).

\section{EARLY REHABILITATION PROGRAM VS STANDARD ONE}

Analyzed studies compare an early start of the rehabilitation program with a "standard" rehabilitation timing. Munin et al. ${ }^{43}$ analyze the early beginning of the hospital rehabilitation path, Liebs ${ }^{42}$ study hydrokinesis early beginning and Monticone ${ }^{44}$ compares an early total weight bearing with a delayed one.

Munin et al. ${ }^{43}$ say that an early beginning of a rehabilitation program after THR could lead to a reduction in LOS but there are not statistically significant difference regarding SF-36 four months after surgery.

Concerning the study by Liebs et al., ${ }^{42}$ hydrotherapy/begun on the $6^{\text {th }}$ day instead of on the $14^{\text {th }}$ day after THR, brings to minor improvements in WOMAC scores at short, mid and long term follow-ups, between group statistically significant there are no differences regarding SF-36.

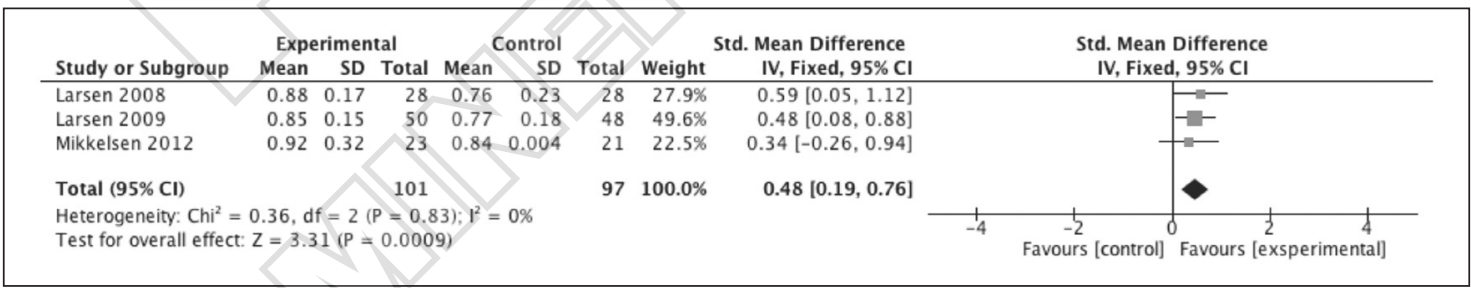

Figure 4.-EQ-5D analysis; 3 months follow-up.

\begin{tabular}{|c|c|c|c|c|c|c|c|c|c|c|}
\hline \multirow[b]{2}{*}{ Study or Subgroup } & \multicolumn{3}{|c|}{ Experimental } & \multicolumn{3}{|c|}{ Control } & \multirow{2}{*}{ Weight } & \multirow{2}{*}{$\begin{array}{l}\text { Std. Mean Difference } \\
\text { IV, Fixed, } 95 \% \mathrm{CI}\end{array}$} & \multirow{2}{*}{\multicolumn{2}{|c|}{$\begin{array}{l}\text { Std. Mean Difference } \\
\text { IV, Fixed, } 95 \% \mathrm{CI}\end{array}$}} \\
\hline & Mean & SD & Total & Mean & SD & Total & & & & \\
\hline Larsen 2008 & 4.2 & 1.8 & 55 & 7.3 & 1.8 & 50 & $41.0 \%$ & $-1.71[-2.16,-1.26]$ & $-1-$ & \\
\hline Larsen 2009 & 4.4 & 1.3 & 28 & 7.3 & 1.5 & 28 & $19.4 \%$ & $-2.04[-2.69,-1.38]$ & $\longrightarrow$ & \\
\hline Stockton 2009 & 8 & 3.3 & 30 & 8.1 & 2.6 & 27 & $30.7 \%$ & $-0.03[-0.55,0.49]$ & & - \\
\hline Suetta 2004 & 10 & 2.4 & 11 & 16 & 7.2 & 9 & $8.9 \%$ & $-1.12[-2.08,-0.16]$ & & \\
\hline Total $(95 \% \mathrm{Cl})$ & & & 124 & & & 114 & $100.0 \%$ & $-1.21[-1.49,-0.92]$ & & \\
\hline \multicolumn{7}{|c|}{$\begin{array}{l}\text { Heterogeneity: } C i^{2}=30.61, d f=3(P<0.00001) ; I^{2}=90 \% \\
\text { Test for overall effect: } Z=8.21(P<0.00001)\end{array}$} & & & $\begin{array}{lll}-4 & -2 & 0 \\
\text { Favours [experimental] }\end{array}$ & $\begin{array}{c}2 \\
\text { Favours [control] }\end{array}$ \\
\hline
\end{tabular}

Figure 5.-LOS analysis. 
TABLE II.-Data extraction

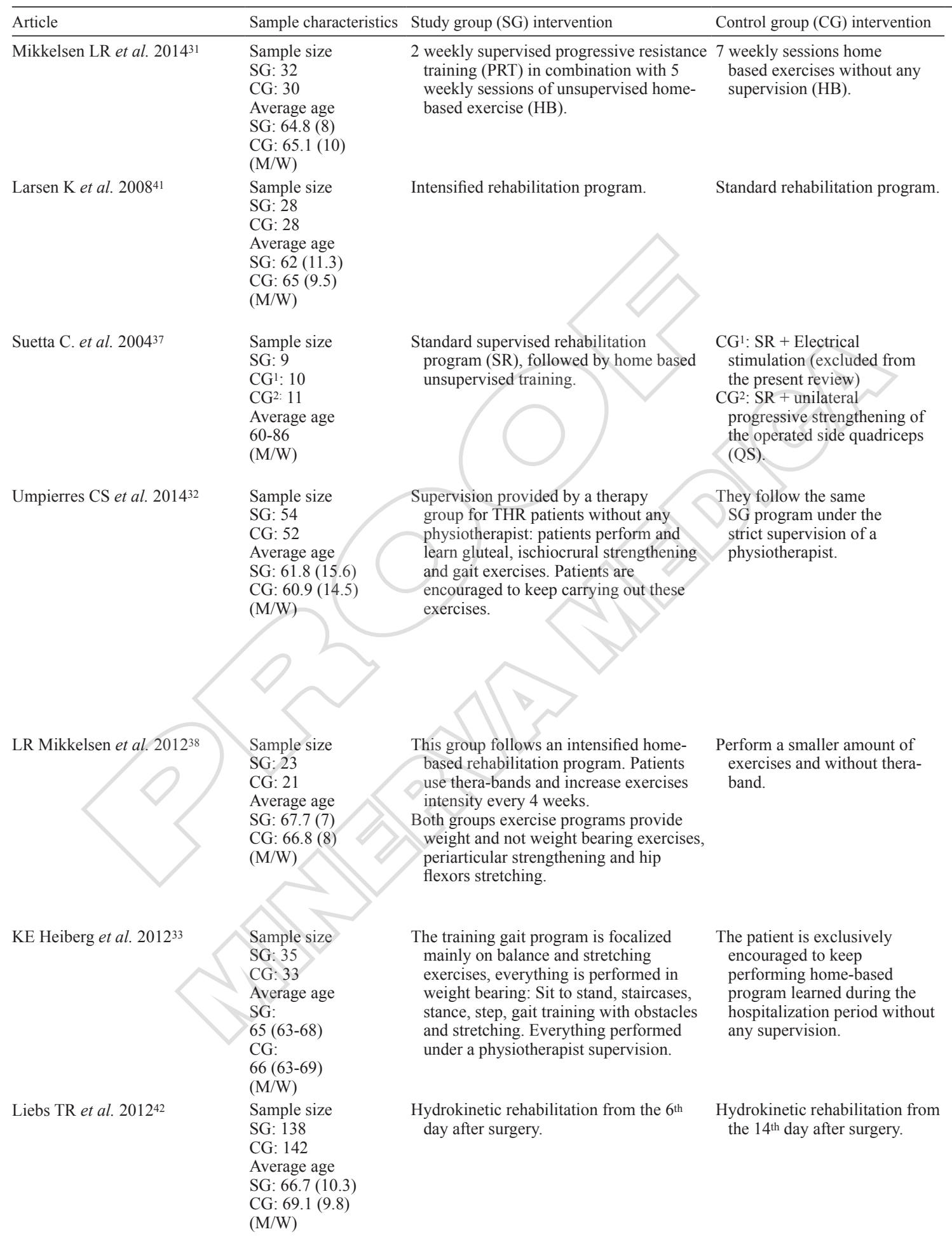




\begin{tabular}{|c|c|c|c|c|}
\hline Timings & Follow-up & Outcome & Results & Jadad Score \\
\hline $\begin{array}{l}\text { SG: beginning } 1 / 3 \text { days after op. } 2 / \mathrm{W} \text { PRT and } \\
\text { 5/W HB } \\
\text { CG: beginning } 1 / 2 \text { days after op. } 7 / \mathrm{W} \text { HB. } \\
\text { Duration of the study: } 10 \text { weeks. }\end{array}$ & $\begin{array}{l}2 \text { weeks, } \\
4 \text { weeks, } \\
6 \text { weeks, } \\
10 \text { weeks, } \\
6 \text { months, } \\
12 \text { months. }\end{array}$ & HOOS & $\begin{array}{l}\text { For what concern HOOS: no between- } \\
\text { group statistically significant } \\
\text { difference. }\end{array}$ & 2 \\
\hline
\end{tabular}

SG: patient mobilization starts the same day of 3 months. the surgery. Treatment duration raise from 2 hours to 4 hours in the second day post-op.

CG: patient mobilization starts the first day after surgery with a standardized intensity. Treatment are provided until discharge day. Length of stay depends on achieving some relevant physical goals.

LOS, EQ-5D Statistically significant between-group differences in both outcomes. In favor of the SG. difference with a lower LOS for the $\mathrm{CG}^{2}$.

SG: 1 hour per day

$\mathrm{CG}^{2}$ : SR 1 hour per day + QS 3 times per week.

Duration of the study: 12 weeks.

LOS

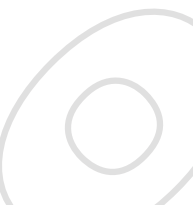

SF-36 The rehabilitation program starts $1 / 2$ days after 20 days. surgery. It is performed 1 hour per day for $5.3 \pm 1.1$ days.

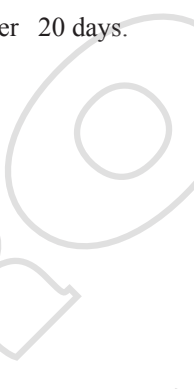

1 month, 3 months. Early beginning of the home-based program
for both groups $(77 \%$ of patients begin the program after 3 days).

2 daily series of exercises were recommended for 12 weeks. Authors estimate a total of 10.1 actual weekly series for the SG and 11.6 for the CG. $[\mathrm{P}=0.37]$

The study is related to the timeframe from the 5 months, $3^{\text {rd }}$ month to the $5^{\text {th }}$ one after surgery. The SG 70 minutes program is performed twice a week for 6 weeks.

\section{2 months.}

HOOS, HHS

In both goups, with regards to physical functions, minimally relevant improvements are described. More relevant improvements are recorded concerning general health and social component. The only statistically significant difference recorded is regarding pain parameters that shows better improvements in the CG.

SF-36 Bodily pain score:

GS: $29.2(2.2)-53.8(2.2)[<0.001]$

GC: 26.1 (2.2)-43.9 (2.2) $[<0.001]$

Data does not provide any statistically significant between-group difference. Exercises performed with thera-band don't seem better than exercises without thera-band. A significant improvement of all the outcomes has been recorded in both groups. 4 SG patients report problems with thara-band exercises. No reported problems in the CG. significant bigger improvements are reported in SG's HHS $(\mathrm{P}=0,05)$. For what concern HOOS and the HHS long term follow up statistically significant differences are not reported.

Both groups underwent treatments 30 minutes long, 3 times a week till the $5^{\text {th }}$ week after surgery.
3 months, 6 months, 12 months, 24 months.
SF-36 WOMAC
Results lead author to say that an early start of hidrikinetic rehabilitation for THR PTs is inadvisable. All WOMAC subscales, at every follow-up are, although not always in a statistically significant manner, worse for the SG. For what concern SF-36 scores, relevant differences are not collected at every follow-up. 
TABLE II.-Data extraction (continues).

\begin{tabular}{|c|c|c|c|}
\hline Article & Sample characteristics & Study group (SG) intervention & Control group (CG) intervention \\
\hline Stockton KA et al. $2009^{39}$ & $\begin{array}{l}\text { Sample size } \\
\text { SG: } 30 \\
\text { CG: } 27 \\
\text { Average age } \\
\text { SG: } 68.3(9.3) \\
\text { CG: } 68.2(10.6) \\
\text { (M/W) }\end{array}$ & $\begin{array}{l}\text { Standard rehabilitation program: at the } \\
\text { beginning focalized on bed exercises and } \\
\text { as soon as possible on weight bearing } \\
\text { exercises: ankle dorsiflexion, squats, hip } \\
\text { flexion, extension and abduction. }\end{array}$ & $\begin{array}{l}\text { Same standardized rhebilitation } \\
\text { program }\end{array}$ \\
\hline Smith TO et al. 2008 e $2009^{34,35}$ & $\begin{array}{l}\text { Sample size } \\
\text { SG: } 30 \\
\text { CG: } 30 \\
\text { Average age } \\
\text { SG: } 66.2(11.3) \\
\text { CG: } 68.1(10.5) \\
\text { (M/W) }\end{array}$ & $\begin{array}{l}\text { Standard gait retraining (SGR). From } \\
\text { first day after surgery going out of bed } \\
\text { experiencing static and dynamic partial } \\
\text { weight bearing. Training proceed by } \\
\text { reducing walking support, increasing } \\
\text { meters and introducing a step and } \\
\text { staircase training. To this program are } \\
\text { added bed exercises: hip flexion, ankle } \\
\text { flexion/extension, isometric gluteal and } \\
\text { quadriceps strengthening. }\end{array}$ & Standard gait retraining (SGR). \\
\hline Galea MP et al. $2008^{36}$ & $\begin{array}{l}\text { Sample size } \\
\text { SG: } 11 \\
\text { CG: } 12 \\
\text { Average age } \\
\text { SG: } 68.6(9.7) \\
\text { CG: } 66.6(7.9) \\
(\mathrm{M} / \mathrm{W})\end{array}$ & $\begin{array}{l}\text { Home based program without any } \\
\text { supervision: sit to stand, active single- } \\
\text { leg stance (loading weight with the } \\
\text { not operated leg), climbing steps, hip } \\
\text { abduction, heel rise, side walking. }\end{array}$ & $\begin{array}{l}\text { Standard rehabilitation program } \\
\text { under the direct supervision } \\
\text { of a physiotherapist, plus a } \\
\text { home-based rehabilitation } \\
\text { program. }\end{array}$ \\
\hline Munin M et al. $1998^{43}$ & $\begin{array}{l}\text { Sample size } \\
\text { SG: } 14 \\
\text { CG: } 12\end{array}$ & . & Standard rehabilitation program. \\
\hline Monticone & $\begin{array}{l}\text { Sample size } \\
\text { SG: } 47 \\
\text { Cg: } 48 \\
\text { Average age } \\
\text { SG: } 69,5(7,5 \\
\text { CG: } 68,8(8, \\
\text { (M/W) }\end{array}$ & $\begin{array}{l}\text { Finalized exercises: stair climbing and } \\
\text { descending, gait training with obstacles, } \\
\text { balance exercises and ADL related } \\
\text { exercises. Patients are encouraged to } \\
\text { abandon any walking aid before the end } \\
\text { of the hospitalization. }\end{array}$ & $\begin{array}{l}\text { Open chain exercises: hip } \\
\text { flexion, extension, abduction } \\
\text { and external rotation, } \\
\text { isometric and isotonic } \\
\text { quadriceps contraction. The } \\
\text { patient is encouraged to keep } \\
\text { using some walking aid till the } \\
\text { end of the third month after } \\
\text { surgery. }\end{array}$ \\
\hline Larsen KR et al. $2009^{40}$ & $\begin{array}{l}\text { Sample size } \\
\text { SG: } 50 \\
\text { CG: } 48 \\
\text { Average age } \\
\text { SG: } 65 \text { (9.6) CG: } 67 \\
(9.8) \\
(\mathrm{M} / \mathrm{W})\end{array}$ & Standard rehabilitation program. & Standard rehabilitation program. \\
\hline
\end{tabular}




\begin{tabular}{|c|c|c|c|c|}
\hline Timings & Follow-up & Outcome & Results & Jadad Score \\
\hline $\begin{array}{l}\text { GC: once a day. } \\
\text { GS: twice a day. } \\
\text { Until the resignation. }\end{array}$ & - & LOS & $\begin{array}{l}\text { There is not statistically significant } \\
\text { between-group difference regarding } \\
\text { LOS. } \\
\text { GS: } 8 \pm 3,3 \\
\text { GC: } 8.1 \pm 2.6 \\
\text { (7\% of PTs was then transferred to a } \\
\text { rehabilitation center). }\end{array}$ & 2 \\
\hline
\end{tabular}

In both groups patients perform the gait 3 days, training at least once per day for the duration 6 weeks, of the hospital stay.

SG add bed exercises 5 times per day.
1 year.

\section{SF-12}

No between-group statistically significant differences are emerged.

After the initial hospitalization period patients 3 months. have been randomized. SG complete an 8-week targeted exercise program while under the direct supervision of a physiotherapist twice a week for 45 minutes and patients perform home based exercises without any supervision on an average of 2,7 times a week. Patients of the CG perform home based exercises on an average of 5,8 times a week.

Patients from both groups are treated twice a day for 60 minutes, 6 days a week; on Sunday they receive a treatment 30 minutes long. SG begins the rehabilitation path 3 days after surgery while the CG 7 days after surgery.

4 months.

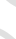

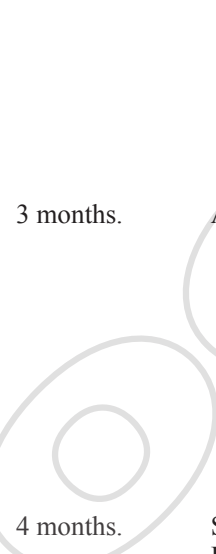

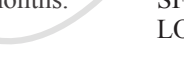

No between-group statistically 1 WOMAC significant differences are emerged

LOS

At the 4 months follow-up doesn't emerge any statistically significant difference for what concern SF-36.

Regarding LOS is notable the reduction in the $\mathrm{SG}$.

SG: $11.7 \pm 2.3$ days

CG: $14.5 \pm 1.9$ days $\mathrm{P}<.001$

The rehabilitation program begins between the 3 weeks, $4^{\text {th }}$ the $7^{\text {th }}$ day postsurgery. Treatment duration

45 minutes.

Treatment frequency:

5/week.

Rehab. cycle duration:

3 weeks.

12 months.
SF-36,

WOMAC
After treatment, scores regarding

WOMAC physical function improve approximately $50 \%$ in the SG and $20 \%$ in the CG. With a minor between-group difference also WOMAC pain and stiffness improved more in the SG than in the CG.

At 12 months follow-up both groups keep improving in a similar proportional way.

SF-36 scores are also in favor of SG in a statistically relevant way.

SG: 4.2 (1.8) days

CG: 7.3 (1.8) days

SG: patient mobilization starts the same day of the surgery. Treatment duration raise from 2 hours to 4 hours in the second day post-op.

CG: patient mobilization starts the first day after surgery with a standardized intensity. Treatment are provided until discharge day. Length of stay depends on achieving some relevant physical goals. 


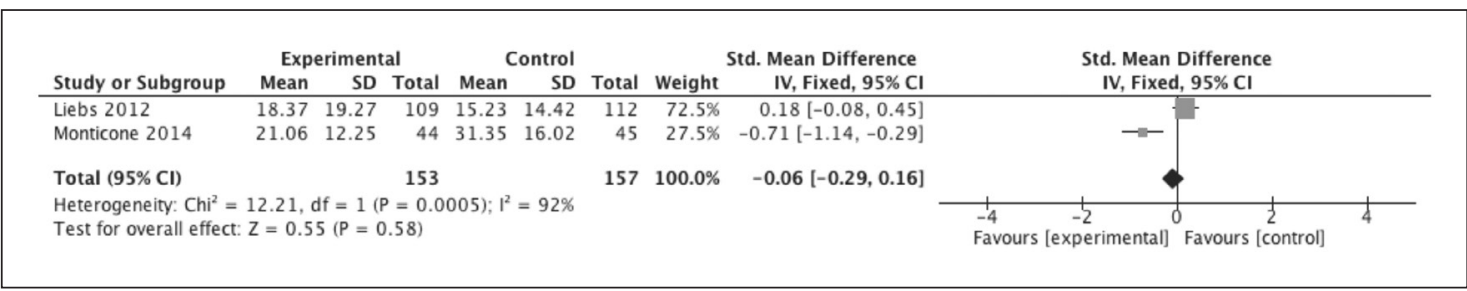

Figure 6.-WOMAC anlysis; 12 months follow-up.

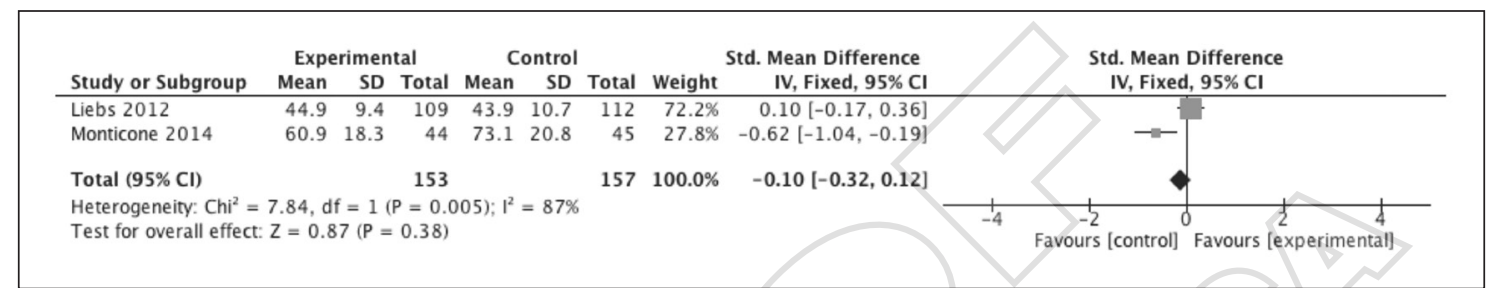

Figure 7.-SF-36 analysis; 12 months follow-up.

Finally, Monticone ${ }^{44}$ says that WOMAC and SF-36 short- and long-term outcomes are better encouraging the patient to leave any walking aid before the end of hospitalization stay.

Long-term (12 months) WOMAC data metaanalysis has been made on two studies with a total amount of 210 patients.

Pool analysis average shows that an intensified rehabilitation program has led to not statistically significant better outcomes (-0.06 points, CI -0.29-0.16; $\mathrm{P}=0.58$ ) (Figure 6).

LOS meta-analysis has been made on two studies (210 patients). Pool analysis average shows that an intensified rehabilitation program does not provide any statistically-significance outcome difference ( -0.10 points, $\mathrm{CI}-0.32-0.12$; $\mathrm{P}=0.38$ ) (Figure 7).

\section{Discussion}

The present study was conducted by health professionals of Sapienza University of Rome and ROMA - Rehabilitation \& Outcome Measures Assessment Association. The research group has carried out of many outcome measures in Italy.45-61

The objective of the study was to analyze outcome differences between heterogeneous rehabilitation programs, paying attention on elements such as program supervision, intensity and start timing.
Regarding the first above mentioned stratification, it is relevant the same amount of treatment minutes between control and study groups for all studies excepted Smith et al. 34,35 This fact led us to analyze more strictly effects influenced by supervision or no supervision. It is shown a lack of relevant differences on every mid and long-term outcome, while at short term follow-up there are some differences in favor of supervised rehabilitation program.

Umpierres et al. ${ }^{32}$ and Heiberg et al.,33 even if the second one performs the analyzed rehabilitation program three months after THR, are the only two studies with a "short term" followup (directly after the treatment period) and they reach similar conclusions. The authors highlight that direct physiotherapist action after THR, had a big relevance for pain reduction, functional recovery and ADL management in the short-term period. Biggest limit of the first study is the lack of mid and long-term follow-up.

Studies with a mid and long-term follow-up, show different results from the two above-mentioned articles. Mikkelsen et al. ${ }^{31}$ say that 10 weeks of supervised progressive resistance training, performed twice a week combined with five weekly session of unsupervised exercises, does not provide better HOOS scores compared to seven weekly session of unsupervised exercises. The bigger limit of the study is the possible presence of selection bias. The Authors might have 
included more motivated patients willing to follow two weekly supervised exercise sessions, fact that could have weakened the external validity of the study.

Galea et al. ${ }^{36}$ analyzed QoL and WOMAC at a mid-term follow-up and no between group relevant differences are shown before and after treatment.

Finally, it seems a bit of a stretch to put Smith $^{34,35}$ data into this discussion, despite conceptually inherence of this stratification. In these articles Smith et al., in line with rest of EBMs, say that adding "bed exercises" to standard treatment does not provide any relevant differences in patient's QoL. ${ }^{34,35}$

Analysis of the first stratification let us affirm that there is a good relation between a supervised rehabilitation program and better short term QoL outcomes.

With regard to the second stratification, ${ }^{37,39-41}$ four out of five of the considered studies, record postoperative length of stay. Meta-analysis results show a statistically significant reduction in length of stay in groups that had followed intensive rehabilitation programs, relevant particularly in the light of QoL outcomes equal or even better compared to control groups. All the studies have recorded a reduction in length of stay, just in Stockton et al. ${ }^{39}$ patients who received physiotherapy twice daily, showed a trend toward earlier achievement of functional milestones; however, this finding did not translate to decreased LOS. Authors argued that in the private hospital setting in Australia, many patients expect a stay of a minimum seven days, which is often a barrier to earlier discharge.

Outside of example, in the other three articles are notable: relevant differences in length of stay: in Suetta ${ }^{37}$ mean \pm standard error LOS was shorter for the intensive "resistance" training group $(10.0 \pm 2.4$ days, $\mathrm{P}<0.05)$ than for the standard rehabilitation group (16.0 7.2 days); shorter of 2,9 days for the intensive early rehabilitation program in Larsen ${ }^{41}$ and of 3.1 days for the same group in Larsen et al. ${ }^{40}$ In the last two articles, as mentioned, this reduction in LOS is even associated with average EQ-5D values at three months, improved of 0.30 points in the intensive rehabilitation group compared to the
0.23 points improvement of the standard rehabilitation group in the first one and of 0.43 points compared to the 0.27 points of the control group in the second one. Authors argue that a shortened hospital stay and an early mobilization lead to less compromised physical functions so, to a faster recovery of them.

Finally, in the fifth article, Mikkelsen et al., ${ }^{38}$ EQ-5D scores recorded are not statically significant but tend to confirm the data obtained by Larsen et al. 40,41 WOMAC scores, recorded after 3 months, does not show any statistically significant difference.

Meta-analyzed data show a relevant statistically significant support to an accelerated rehabilitation program with regard to LOS and midterm (3 months) EQ-5D scores.

This led us to strongly prefer an accelerated rehabilitation program that, without any apparent side-effect, seems to result in a faster recovery, a reduced LOS and equal or better mid-term QoL outcomes compared to a standard rehabilitation program.

The last comparison is between an early rehabilitation program and a standard one, includes heterogeneous studies. The three included studies analyze the early beginning: of idrokinesis, ${ }^{42}$ of the standard rehabilitation program, ${ }^{43}$ or of total weight bearing. ${ }^{44}$ Probably due to the different nature of the proposed treatment, Liebs et al. results are not congruent to the other. Opposite effects of early aquatic therapy were seen between TKA and THA. For THA patients all WOMAC outcomes were superior in the late aquatic therapy group (14 days post-op. instead of 6). The article has a good sample size of 280 THR patients and a Jadad Score of 3. It does not show relevant limits, just a high drop-out rate: from a $90 \%$ rate after 3 months to a follow-up rate of $74 \%$ after 24 months. However, 3 months follow-up outcomes are perfectly in line with mid and long term outcomes, this led us considerate it not as a massive bias. Authors are not able to explain why but, total knee arthroplasty (TKA) patients show contradictory outcomes, however, for THR patients, early hydrokinetic physiotherapy seems inadvisable.

Analyzing the following article, Monticone et al.,44 we can say that postpone total weight 
bearing until three months after the operation is contraindicated, unless special circumstances arise. Included patients had multiple comorbidities, still requiring medical care 4/7 days after the operation and/or have insufficient home support. Control group (CG) keep using walking aids for three months after surgery while in the study group (SG) patients are encouraged to abandon any walking aid before the end of the hospitalization. After training, the WOMAC Index - physical function score decreased by almost $50 \%$ in the SG and by about $20 \%$ in the CG. Also, the decrease in pain intensity and the improvement in ADL performance were more significant in the SG than in the CG. In terms of QoL, the physical function, physical role and general health subscales revealed significant between-group differences after training in favor of the SG.

From the third article, Munin et al. ${ }^{43}$ is notable that an early beginning of the same rehabilitation program (three-dimensional days post-surgery instead of 7 days) led to achieve same results, concerning SF-36, in less time without any sideeffect.

Concerning the comparison between an early beginning and a standard one, due to article heterogeneity, any generalization seems possible.

\section{Conclusions}

Considering the great rise of THR surgeries, is important to minimize costs and logistic efforts for the postoperative rehabilitation program ensuring identical or better outcomes.

Thinking of that and of RCTs data it seems evident that, while recognizing physiotherapist as a key element of the rehabilitation program, postoperative treatment should focus on an unsupervised rehabilitation program after a first period of a supervised intensive rehabilitation program.

\section{References}

1. Litwic A, Edwards MH, Dennison EM, Cooper C. Epidemiology and burden of osteoarthritis. Br Med Bull 2013;105:185-99.

2. Inoue K, Hukuda S, Fardellon P, Yang ZQ, Nakai M, Katayama K, et al. Prevalence of large-joint osteoarthritis in Asian and Caucasian skeletal populations. Rheumatology (Oxford) 2001;40:70-3.
3. Salaffi F, De Angelis R, Grassi W; MArche Pain Prevalence; INvestigation Group (MAPPING) study. Prevalence of musculoskeletal conditions in an Italian population sample: results of a regional community-based study. I. The MAPPING study. Clin Exp Rheumatol 2005;23:819-28. [P]

4. Mannoni A, Briganti MP, Di Bari M, Ferrucci L, Costanzo $\mathrm{S}$, Serni U, et al. Epidemiological profile of symptomatic osteoarthritis in older adults: a population based study in Dicomano, Italy. Ann Rheum Dis 2003;62:576-8.

5. Greinacher A, Fendrich K, Hoffmann W. Demographic changes: the impact for safe blood supply. Transfus Med Hemother 2010;37:141-8.

6. Jordan KM, Arden NK, Doherty M, Bannwarth B, Bijlsma JW, Dieppe P, et al.; Standing Committee for International Clinical Studies Including Therapeutic Trials ESCISIT. EULAR Recommendations 2003: an evidence based approach to the management of knee osteoarthritis: Report of a Task Force of the Standing Committee for International Clinical Studies Including Therapeutic Trials (ESCISIT). Ann Rheum Dis 2003;62:1145-55.

7. Juhakoski R, Tenhonen S, Anttonen T, Kauppinen T, Arokoski JP. Factors affecting self-reported pain and physical function in patients with hip osteoarthritis. Arch Phys Med Rehabil 2008;89:1066-73.

8. Gilbey HJ, Ackland TR, Wang AW, Morton AR, Trouchet $\mathrm{T}$, Tapper J. Exercise improves early functional recovery after total hip arthroplasty. Clin Orthop Relat Res 2003;(408):193200.

9. Hunter GR, McCarthy JP, Bamman MM. Effects of resistance training on older adults. Sports Med 2004;34:329-48.

10. Kettunen JA, Kujala UM. Exercise therapy for people with rheumatoid arthritis and osteoarthritis. Scand J Med Sci Sports 2004;14:138-42.

11. Rasch A, Dalén N, Berg HE. Test methods to detect hip and knee muscle weakness and gait disturbance in patients with hip osteoarthritis. Arch Phys Med Rehabil 2005;86:2371-6.

12. Gamble R, Wyeth-Ayerst J, Johnson EL, Searle WA, Beecham S; American College of Rheumatology Subcommittee on Osteoarthritis Guidelines. Recommendations for the medical management of osteoarthritis of the hip and knee: 2000 update. Arthritis Rheum 2000;43:1905-15.

13. Swanson EA, Schmalzried TP, Dorey FJ. Activity recommendations after total hip and knee arthroplasty: a survey of the American Association for Hip and Knee Surgeons. J Arthroplasty 2009;24(Suppl):120-6.

14. Kuster MS. Exercise recommendations after total joint replacement: a review of the current literature and proposal of scientifically based guidelines. Sports Med 2002;32:433-45.

15. Ethgen $O$, Bruyère $O$, Richy $F$, Dardennes $C$, Reginster JY. Health-related quality of life in total hip and total knee arthroplasty. A qualitative and systematic review of the literature. J Bone Joint Surg Am 2004;86:963-74.

16. Kennedy DM, Hanna SE, Stratford PW, Wessel J, Gollish JD. Preoperative function and gender predict pattern of functional recovery after hip and knee arthroplasty. J Arthroplasty 2006;21:559-66.

17. Röder C, Staub LP, Eggli S, Dietrich D, Busato A, Müller $\mathrm{U}$. Influence of preoperative functional status on outcome after total hip arthroplasty. J Bone Joint Surg Am 2007;89:11-7.

18. van den Akker-Scheek I, Stevens M, Bulstra SK, Groothoff JW, van Horn JR, Zijlstra W. Recovery of gait after short-stay total hip arthroplasty. Arch Phys Med Rehabil 2007;88:361-7.

19. Reininga IH, Zijlstra W, Wagenmakers R, Boerboom AL, Huijbers BP, Groothoff JW, et al. Minimally invasive and 
computer-navigated total hip arthroplasty: a qualitative and systematic review of the literature. BMC Musculoskelet Disord 2010;11:92.

20. Bachmeier CJ, March LM, Cross MJ, Lapsley HM, Tribe KL, Courtenay BG, et al.; Arthritis Cost and Outcome Project Group. A comparison of outcomes in osteoarthritis patients undergoing total hip and knee replacement surgery. Osteoarthritis Cartilage 2001;9:137-46.

21. Trudelle-Jackson E, Emerson R, Smith S. Outcomes of total hip arthroplasty: a study of patients one year postsurgery. J Orthop Sports Phys Ther 2002;32:260-7.

22. Jensen C, Aagaard P, Overgaard S. Recovery in mechanical muscle strength following resurfacing vs standard total hip arthroplasty - a randomised clinical trial. Osteoarthritis Cartilage 2011;19:1108-16.

23. Rasch A, Dalén N, Berg HE. Muscle strength, gait, and balance in 20 patients with hip osteoarthritis followed for 2 years after THA. Acta Orthop 2010;81:183-8.

24. Sicard-Rosenbaum L, Light KE, Behrman AL. Gait, lower extremity strength, and self-assessed mobility after hip arthroplasty. J Gerontol A Biol Sci Med Sci 2002;57:M47-51.

25. Perron M, Malouin F, Moffet H, McFadyen BJ. Threedimensional gait analysis in women with a total hip arthroplasty. Clin Biomech (Bristol, Avon) 2000;15:504-15.

26. Beaulieu ML, Lamontagne M, Beaulé PE. Lower limb biomechanics during gait do not return to normal following total hip arthroplasty. Gait Posture 2010;32:269-73.

27. Minns Lowe CJ, Barker KL, Dewey ME, Sackley CM. Effectiveness of physiotherapy exercise following hip arthroplasty for osteoarthritis: a systematic review of clinical trials. BMC Musculoskelet Disord 2009;10:98

28. Okoro T, Ramavath A, Howarth J, Jenkinson J, Maddison $\mathrm{P}$. Andrew $\mathrm{JG}$, et al. What does standard rehabilitation practice after total hip replacement in the UK entail? Results of a mixed methods study. BMC Musculoskelet Disord 2013;14:91.

29. Medical Advisory Secretariat. Physiotherapy rehabilitation after total knee or hip replacement: an evidence-based analysis. Ont Health Technol Assess Ser 2005;5:1-91.

30. Moher D, Shamseer L, Clarke M, Ghersi D, Liberati A, Petticrew M, et al.; PRISMA-P Group. Preferred reporting items for systematic review and meta-analysis protocols (PRISMA-P) 2015 statement. Syst Rev 2015;4:1.

31. Mikkelsen LR, Mechlenburg I, Søballe K, Jørgensen LB, Mikkelsen S, Bandholm T, et al. Effect of early supervised progressive resistance training compared to unsupervised home-based exercise after fast-track total hip replacement applied to patients with preoperative functional limitations. A single-blinded randomised controlled trial. Osteoarthritis Cartilage 2014;22:2051-8.

32. Umpierres CS, Ribeiro TA, Marchisio ÂE, Galvão L, Borges IN, Macedo CA, et al. Rehabilitation following total hip arthroplasty evaluation over short follow-up time: randomized clinical trial. J Rehabil Res Dev 2014;51:1567-78.

33. Heiberg KE, Bruun-Olsen V, Ekeland A, Mengshoel AM. Effect of a walking skill training program in patients who have undergone total hip arthroplasty: followup one year after surgery. Arthritis Care Res (Hoboken) 2012;64:415-23.

34. Smith TO, Mann CJ, Clark A, Donell ST. Bed exercises following total hip replacement: a randomised controlled trial. Physiotherapy 2008;94:286-91.

35. Smith TO, Mann CJ, Clark A, Donell ST. Bed exercises following total hip replacement: 1 year follow-up of a singleblinded randomised controlled trial. Hip Int 2009;19:268-73.

36. Galea MP, Levinger $P$, Lythgo N, Cimoli C, Weller R,
Tully E, et al. A targeted home- and center-based exercise program for people after total hip replacement: a randomized clinical trial. Arch Phys Med Rehabil 2008;89:1442-7.

37. Suetta C, Magnusson SP, Rosted A, Aagaard P, Jakobsen AK, Larsen LH, et al. Resistance training in the early postoperative phase reduces hospitalization and leads to muscle hypertrophy in elderly hip surgery patients - a controlled, randomized study. J Am Geriatr Soc 2004;52:2016-22.

38. Mikkelsen LR, Mikkelsen SS, Christensen FB. Early, intensified home-based exercise after total hip replacement-a pilot study. Physiother Res Int 2012;17:214-26.

39. Stockton KA, Mengersen KA. Effect of multiple physiotherapy sessions on functional outcomes in the initial postoperative period after primary total hip replacement: a randomized controlled trial. Arch Phys Med Rehabil 2009;90:1652-7.

40. Larsen $\mathrm{K}$, Hansen TB, Thomsen PB, Christiansen T, Søballe K. Cost-effectiveness of accelerated perioperative care and rehabilitation after total hip and knee arthroplasty. J Bone Joint Surg Am 2009;91:761-72.

41. Larsen K, Sørensen OG, Hansen TB, Thomsen PB Søballe K. Accelerated perioperative care and rehabilitation intervention for hip and knee replacement is effective: a randomized clinical trial involving 87 patients with 3 months of follow-up. Acta Orthop 2008;79:149-59.

42. Liebs TR, Herzberg W, Rüther W, Haasters J, Russlies M, Hassenpflug J; Multicenter Arthroplasty Aftercare Project. Multicenter randomized controlled trial comparing early versus late aquatic therapy after total hip or knee arthroplasty. Arch Phys Med Rehabil 2012;93:192-9.

43. Munin MC, Rudy TE, Glynn NW, Crossett LS, Rubash HE. Early inpatient rehabilitation after elective hip and knee arthroplasty. JAMA 1998;279:847-52.

44. Monticone M, Ambrosini E, Rocca B, Lorenzon C, Ferrante S, Zatti G. Task-oriented exercises and early full weight-bearing contribute to improving disability after total hip replacement: a randomized controlled trial. Clin Rehabil 2014;28:658-68.

45. Galeoto G, Berardi A, De Santis R, Di Valentini L, Beccasio R, Marquez MA, et al. Validation and cross-cultural adaptation of the Van Lieshout test in an Italian population with cervical spinal cord injury: a psychometric study. Spinal Cord Ser Cases 2018;4:49.

46. Massai P, Colalelli F, Sansoni J, Valente D, Tofani M, Fabbrini G, et al. Reliability and Validity of the Geriatric Depression Scale in Italian Subjects with Parkinson's Disease. Parkinsons Dis 2018;2018:7347859.

47. Galeoto G, Colalelli F, Massai P, Berardi A, Tofani M, Pierantozzi M, et al. Quality of life in Parkinson's disease: Italian validation of the Parkinson's Disease Questionnaire (PDQ-39-IT). Neurol Sci 2018;39:1903-9.

48. Galeoto G, Sansoni J, Scuccimarri M, Bruni V, De Santis $\mathrm{R}$, Colucci M, et al. A Psychometric Properties Evaluation of the Italian Version of the Geriatric Depression Scale. Depress Res Treat 2018;2018:1797536.

49. Galeoto G, Colucci M, Guarino D, Esposito G, Cosma E, De Santis R, et al. Exploring Validity, Reliability, and Factor Analysis of the Quebec User Evaluation of Satisfaction with Assistive Technology in an Italian Population: A CrossSectional Study. Occup Ther Health Care 2018;32:380-92.

50. Covotta A, Gagliardi M, Berardi A, Maggi G, Pierelli F, Mollica R, et al. Physical activity scale for the elderly: Translation, cultural adaptation, and validation of the Italian version. Curr Gerontol Geriatr Res 2018;2018:8294568.

51. Tofani M, Candeloro C, Sabbadini M, Lucibello L, Figura $\mathrm{M}$, Fabbrini G, et al. The psychosocial impact of assistive de- 
vice scale: italian validation in a cohort of nonambulant people with neuromotor disorders. Assist Technol 2018;25:1-6.

52. Berardi $A$, Biondillo $A$, Màrquez MA, De Santis R, Fabbrini G, Tofani M, et al. Validation of the short version of the Van Lieshout Test in an Italian population with cervical spinal cord injuries: a cross-sectional study. Spinal Cord 2019;57:339-45.

53. Berardi A, De Santis R, Tofani M, Márquez MA, Santilli $\mathrm{V}$, Rushton PW, et al. The Wheelchair Use Confidence Scale: italian translation, adaptation, and validation of the short form. Disabil Rehabil Assist Technol 2018;13:575-80.

54. Parente M, Tofani M, De Santis R, Esposito G, Santilli V, Galeoto G. The role of the occupational therapist in disaster areas: systematic review. Occup Ther Int 2017;2017:6474761.

55. Nobilia M, Culicchia G, Tofani M, De Santis R, Savona A, Guarino D, et al. Italian Version of the Jebsen-Taylor Hand Function Test for the Assessment of Hand Disorders: A CrossSectional Study. Am J Occup Ther 2019;73:p1, p6.

56. Tofani M, Nobilia M, Culicchia G, Esposito G, Savona A, Tashi I, et al. The Italian version of rheumatoid arthritis pain scale (IT-RAPS): psychometric properties on community and clinical samples. Reumatismo 2019;71:13-8.
57. Galeoto G, Iori F, De Santis R, Santilli V, Mollica $\mathrm{R}$, Marquez MA, et al. The outcome measures for loss of functionality in the activities of daily living of adults after stroke: a systematic review. Top Stroke Rehabil 2019;26: 236-45.

58. Berardi A, Dhrami L, Tofani M, Valente D, Sansoni J, Galeoto G. Cross-cultural adaptation and validation in the Italian population of the wolf motor function test in patients with stroke. Funct Neurol 2018;33:229-53.

59. Dattoli S, Colucci M, Soave MG, De Santis R, Segaletti $\mathrm{L}$, Corsi C, et al. Evaluation of pelvis postural systems in spinal cord injury patients: outcome research. J Spinal Cord Med 2018;18:1-13

60. Attanasio G, Camerota F, Ralli M, Galeoto G, La Torre $\mathrm{G}$, Galli $\mathrm{M}$, et al. Does focal mechanical stimulation of the lower limb muscles improve postural control and sit to stand movement in elderly? Aging Clin Exp Res 2018;30: 1161-6.

61. Murgia M, Bernetti A, Delicata M, Massetti C, Achilli $\mathrm{EM}$, Mangone $\mathrm{M}$, et al. Inter- and intra-interviewer reliability of Italian version of Pediatric Evaluation of Disability Inventory (I-PEDI). Ann Ig 2018;30:153-61.

Conflicts of interest.-The authors certify that there is no conflict of interest with any financial organization regarding the material discussed in the manuscript.

Manuscript accepted: March 27, 2019. - Manuscript received: March 17, 2019. 